\title{
Successful treatment of Acute Fulminant Liver Failure due to Hepatitis B virus with Entecavir in patients with contra-indications to liver transplant
}

\author{
Mukul Bhattarai, Pardeep Bansal, Michael Komar, Robert E. Smith, Hitekshya Nepal \\ Geisinger Health System, Danville, PA, United States.
}

\begin{abstract}
Accepted on
May 15th, 2013

DOI Name

http://dx.doi.org/10.3126/jaim.v2i2.8780

Keywords

Entecavir, Liver transplant, Fulminant Hepatic

Failure, Hepatitis B Virus

Citation

Mukul Bhattarai, Pardeep Bansal, Michael Komar, Robert E. Smith, Hitekshya Nepal. Successful treatment of Acute Fulminant Liver Failure due to Hepatitis B virus with Entecavir in patients with contra-indications to liver transplant. Journal of Advances in Internal Medicine 2013;02(02):67-70.
\end{abstract}

\begin{abstract}
There are no randomized clinical trials on efficacy of Entecavir in Fulminant Hepatic Failure (FHF) due to Hepatitis B Virus (HBV). Definitive treatment of FHF remains Liver Transplant. However, availability of cadaveric donor organs is limited, and many of the patients with FHF may not be candidates for Liver Transplantation. There are only few case reports on beneficial effects of Entecavir in FHF due to HBV. We present 2 cases of FHF due to HBV. Both patients had severe liver cell damage among which one was immunocompromised. Transaminases were elevated up to 200 times the normal. Both were not transplant candidates, and were successfully treated with Entecavir resulting in significant clinical and transaminases improvement within 7 days of starting Entecavir.
\end{abstract}

\section{INTRODUCTION}

Acute fulminant liver failure refers to the rapid deterioration of liver synthetic function and encephalopathy typically within 8 weeks of the onset of symptoms in a patient with a previously healthy liver. ${ }^{6}$ Hepatitis B virus (HBV) is probably the most common viral cause of FHF. $^{7}$ Fulminant liver failure due to hepatitis B viral (HBV) infection can have mortality of 60 to $90 \% .^{5}$ The only therapy proven to improve patient outcome in FHF is orthotropic liver transplantation, which is associated with one-year survival rates of greater than 80 percent. ${ }^{8}$ Prior to transplantation, most series suggested less than $15 \%$ survival. ${ }^{9}$ However, in this era of liver transplantation, the availability of cadaveric donor organs is limited. Even when available it would be contraindicated in different grounds. Moreover, there are many regions in the world where transplant facilities are unavailable or unaffordable resulting in high mortality of FHF secondary to HBV. Therefore in such scenario Entecavir therapy seems to be beneficial shown in few case reports including ours. ${ }^{2-4,16}$ We present 2 cases of FHF due to HBV, who were not transplant candidates, and were successfully treated with Entecavir and supportive care in our transplant center.

Case 1: A 45 year old female was transferred to our medical center with FHF from HBV. She presented with jaundice and altered mental status. Liver Function Tests (LFT's) were remarkable for ALT 6420, AST 6470, total bilirubin 9.65, INR 5.5 (Table-1 and Graph 1). Her ammonia level at presentation was elevated to $189 \mathrm{umol} / \mathrm{L}$, which went upto $201 \mathrm{umol} / \mathrm{L}$ next day. Non contrast CT of head showed mild cerebral edema without any signs of hemorrhage.

She had a history of intravenous drug abuse and her toxicology screen was positive for opium and cocaine. HBV DNA was 1432 copies/mL. She was deemed not to be a liver transplant candidate because of significant socio-psychiatric issues including drug abuse and depression requiring hospitalizations in past. She was admitted in intensive care unit, was intubated and started on $3 \%$ hypertonic normal saline with intracranial pressure monitoring. Liver biopsy revealed Acute Fulminant Hepatitis with necrosis of $50 \%$ of the hepatic parenchyma (Figure 1 and 2). She was started on Entecavir $1 \mathrm{mg}$ daily. From day 4 on treatment, she started showing slight improvement in her mental status and LFT's started to improve (Table 1 and Graph 1). She was eventually extubated and was discharged home on Entecavir on day 11. In hepatology clinic follow up in 2 weeks, she was almost completely back to her baseline activity with mildly elevated ALT and AST and her Entecavir was stopped.

\footnotetext{
* Corresponding author

Mukul Bhattarai

100 N Academy Ave, Danville

Pennsylvania, USA 17822

Email: drmukulbhattarai@gmail.com
} 


\section{ENTECAVIR given here}

\begin{tabular}{|l|c|c|c|c|c|c|c|c|c|c|c|}
\hline LFT & $\begin{array}{c}\text { Day } \\
\mathbf{1}\end{array}$ & $\begin{array}{c}\text { Day } \\
\mathbf{2}\end{array}$ & $\begin{array}{c}\text { Day } \\
\mathbf{3}\end{array}$ & $\begin{array}{c}\text { Day } \\
\mathbf{4}\end{array}$ & $\begin{array}{c}\text { Day } \\
\mathbf{5}\end{array}$ & $\begin{array}{c}\text { Day } \\
\mathbf{6}\end{array}$ & $\begin{array}{c}\text { Day } \\
\mathbf{7}\end{array}$ & $\begin{array}{c}\text { Day } \\
\mathbf{8}\end{array}$ & $\begin{array}{c}\text { Day } \\
\mathbf{9}\end{array}$ & $\begin{array}{c}\text { Day } \\
10\end{array}$ & $\begin{array}{c}\text { Day } \\
\mathbf{1 1}\end{array}$ \\
\hline ALT & 6420 & 7129 & 5475 & 4762 & 5525 & 3898 & 3085 & 2471 & 2468 & 1322 & 1082 \\
\hline AST & 6470 & 4828 & 3332 & 2637 & 2215 & 1219 & 927 & 500 & 461 & 450 & 432 \\
\hline INR & 5.5 & 4.27 & 2.88 & 3.13 & 4.33 & 2.21 & 2.10 & 1.85 & 2.39 & 1.80 & 1.6 \\
\hline
\end{tabular}

Table 1: Trend of liver functions tests in case 1

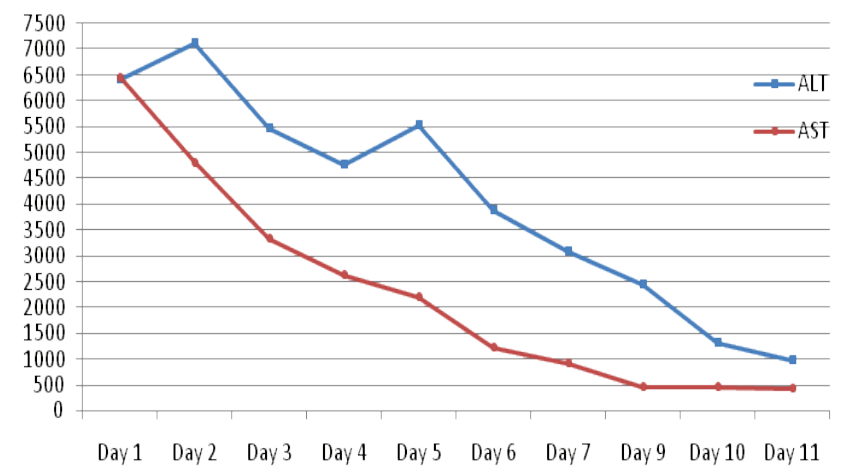

Graph 1: Trend of AST and ALT in Case 1

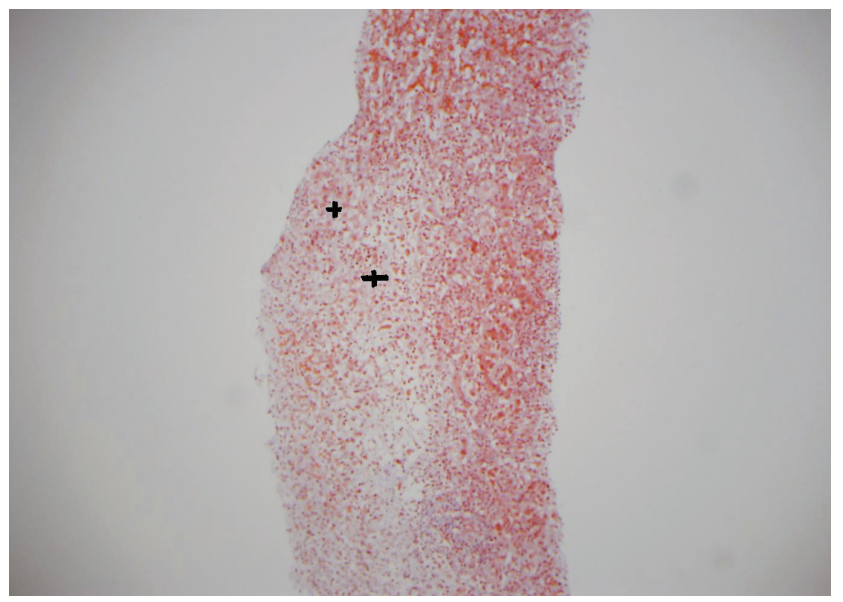

Figure 1 : Trichrome staining showing confluent necrosis of the hepatocytes (+ signs)

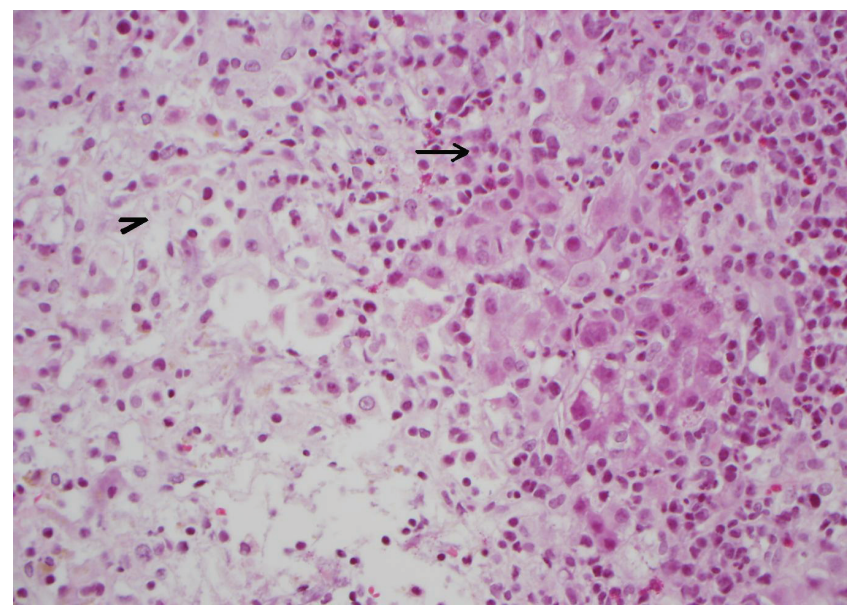

Figure 2 : H\&E showing interface of mononuclear cells infiltration (arrow), necrotic areas ( arrow head)
Case 2: A 84 year old female with Large B cell Lymphoma who was started on Rituxan about 4 weeks ago, presented with jaundice from reactivation of chronic HBV infection. LFT's were remarkable for ALT 4516, AST 3007, total bilirubin 16.3, INR 1.46. HBV PCR was $2547607 \mathrm{IU} / \mathrm{ml}$. She started developing confusion on the day after admission. CT head did not show any evidence of an acute intracranial process. She was not a liver transplant candidate because of her advanced age and Lymphoma. She was started on Entecavir 1mg daily with improving her LFTs as shown in Table 2 and Graph 2. She received Entecavir of total seven days.

\section{ENTECAVIR given here}

\begin{tabular}{|c|c|c|c|c|c|c|c|c|c|c|c|}
\hline LFT & DAY & Day & Day & Day & Day & Day & Day & Day & Day & Day & Day \\
$\mathbf{2}$ & $\mathbf{3}$ & $\mathbf{4}$ & $\mathbf{5}$ & $\mathbf{6}$ & $\mathbf{7}$ & $\mathbf{8}$ & $\mathbf{9}$ & $\mathbf{1 0}$ \\
\hline ALT & 4516 & $\mathbf{4 6 5 2}$ & $\mathbf{6 7 7 3}$ & $\mathbf{7 7 6 0}$ & $\mathbf{7 3 6 0}$ & 6349 & 5040 & $\mathbf{4 5 9 6}$ & 3579 & 2986 & 1845 \\
\hline AST & 3007 & $\mathbf{9 7 2}$ & 3914 & 4002 & 168 & 3611 & 3195 & 3069 & 2484 & 2140 & 1480 \\
\hline INR & 1.46 & 1.81 & 1.91 & 2.62 & 4.28 & 4.50 & 4.11 & 7.69 & 3.46 & 2.60 & 2.10 \\
\hline
\end{tabular}

Table 2: Trend of Liver function tests in Case 2.

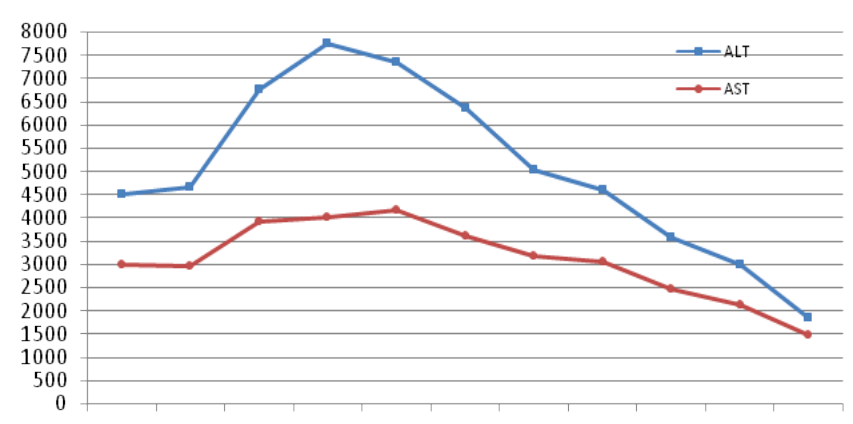

Day 1 Day 2 Day 3 Day 4 Day 5 Day 6 Day 7 Day 8 Day 9 Day 10 Day 11

Graph 2: Trend of AST and ALT in case 2

\section{DISCUSSION:}

The nucleoside analog, Lamivudine is the most commonly used drug for HBV reactivation and FHF from HBV. It has been shown to be safe in reactivation and in severe acute or fulminant hepatitis B. ${ }^{12}$ The efficacy of lamivudine is hampered by the high rate of drug resistance mutations within the HBV polymerase gene that are associated with treatment failure. ${ }^{13}$ Entecavir was approved in 2006 for the treatment of chronic hepatitis $B$ and offers the advantage of a higher resistance barrier than lamivudine. ${ }^{13}$

As per AASLD 2011 practice guidelines, the nucleoside analog lamivudine (and possibly other nucleos(t)ide analogues), used widely in the treatment of chronic hepatitis $B$, may be considered in patients with acute hepatitis $B$, although evidence of efficacy is equivocal. ${ }^{10-11}$ In another case series on two patients with severe acute hepatitis B were immediately started treatment with lamivudine in view of the prolonged prothrombin time. ${ }^{16}$ But there was no evidence of adequate recovery of liver function. Improvement followed after switching the antiviral therapy to Entecavir or to an add-on with 
Adefovir demonstrating that Entecavir seem to be efficacious in acute hepatitis $B$ therapy when lamivudine has failed. ${ }^{16}$ There is very limited experience with the use of newer nucleotide analogue like Entecavir and Tenefovir in the treatment of FHF and $\mathrm{HBV}$ reactivation. ${ }^{1-4,11}$ Based on these case reports and case series, we tried Entecavir in our two patients, who were not transplant candidate, with successful outcome.

The reactivation of $\mathrm{HBV}$ is common with immunosuppressive therapy if they are not on anti- HBV prophylaxis as in our Case 2. All patients prior to initiation of immunosuppressive therapy should be checked for HBV. ${ }^{17}$ Patients found to be positive for HBsAg who are to begin immunosuppressive therapy should be treated prophylactically with a nucleos(t)ide analog, and that treatment should be continued for six months after completion of immunosuppressive therapy. ${ }^{11}$ In the case series published by Brost et al, one patient on Lamivudine prophylaxis had reactivation of HBV infection and was successfully treated with Entecavir. ${ }^{13}$ There is a single case report from Japan of drug-induced liver injury caused by Entecavir for treatment of hepatitis $B$ virus reactivation during rituximab/cyclophosphamide /doxorubicin/vincristine/prednisolone (RCHOP) in a patient with non-Hodgkin lymphoma. ${ }^{14}$

Other side effect which is reported with Entecavir in a case series of 16 patients is Lactic acidosis. ${ }^{15}$ In this case series 5 out of 16 patients treated with Entecavir developed lactic acidosis. All patients who developed lactic acidosis had highly impaired liver function (Model for End-Stage Liver Disease [MELD] score >or= 20). Lactic acidosis (lactate $26-200 \mathrm{mg} / \mathrm{dL}, \mathrm{pH}$ 7.02-7.40, base excess $-5 \mathrm{mmol} / \mathrm{L}$ to $-18 \mathrm{mmol} / \mathrm{L}$ ) occurred between 4 and 240 days after treatment initiation with Entecavir. Lactic acidosis was lethal in one patient but resolved in the other cases after termination/interruption of Entecavir treatment. Our both patient were monitored for lactic acidosis and both patients had lactic acid level of less than $4 \mathrm{mmol} / \mathrm{L}$ during the treatment.

\section{CONCLUSION:}

Our cases suggest that a prompt and timely initiation of antiviral therapy nucleoside inhibitor such as Entecavir in patients with FHF from HBV seems to be beneficial. Design of a multicenter double blind randomized trial to compare the efficacy of lamivudine and newer antiviral agents (like Entecavir or Tenofovir) in FHF from HBV would be helpful. However, such a trial is difficult to perform as these cases are not frequent and are associated with high mortality rate. In the meantime, Entecavir appears promising as it is well tolerated in patients with FHF. It has potent antiviral activity with low rate of drug resistance and should be considered in patients with FHF from HBV who are not transplant candidates. These rare cases would be extremely useful to help physicians making the decision to consider Entecavir in acute fulminant hepatitis who is not a transplant candidate or where such transplant facilities are not available.

\section{REFERENCES}

1. Tillmann HL, Zachou K, Dalekos GN. Management of severe acute to fulminant hepatitis B: to treat or not to treat or when to treat? Liver Int. 2012 Apr;32(4):54453.

2. De Socio GV, Mercuri A, Di Candilo F et al. Entecavir to treat severe acute hepatitis B. Scand J Infect Dis. 2009;41:703-704.

3. Girke J, Wedemeyer $\mathrm{H}$, Wiegand J, Manns MP, Tillmann $\mathrm{HL}$. Acute hepatitis $\mathrm{B}$ : is antiviral therapy indicated? Two case reports. Dtsch Med Wochenschr. 2008;133:11781782.

4. Jochum C, Gieseler RK, Gawlista I, Fiedler A, Manka P, Saner FH, Roggendorf M, Gerken G, Canbay A. Hepatitis B-associated acute liver failure: immediate treatment with entecavir inhibits hepatitis B virus replication and potentially its sequelae. Digestion. 2009;80:235-40.

5. Antoniu E, Luca V. Features of clinical evolution of severe acute viral hepatitis. Series of 72 cases. Rev Med Chir Soc Med Nat lasi. 2010;114:95-100.

6. Trey C, Davidson LS. The management of fulminant

hepatic failure. In: Progress in Liver Disease, Popper $\mathrm{H}$, Shaffner F (Eds), Grune and Stratton, New York 1970. p.282.

7. Ostapowicz G, Fontana RJ, Schiødt FV, et al. Results of a prospective study of acute liver failure at 17 tertiary care centers in the United States. Ann Intern Med 2002; 137:947.

8. Polson J, Lee WM, American Association for the Study of Liver Disease. AASLD position paper: the management of acute liver failure. Hepatology 2005; 41:1179.

9. Polson J, Lee WM. AASLD position paper: the management of acute liver failure. Hepatology 2005 May;41(5):1179-97.

10. Mindikoglu AL, Regev A, Schiff ER. Hepatitis B reactivation after cytotoxic chemotherapy: the disease and its prevention. Clin Gastroenterol Hepatol 2006:4:1076-81.

11. Lok ASF, McMahon BJ. AASLD Practice Guideline, Chronic Hepatitis B: Update of Recommendation 2009;50:661-2.

12. Tillmann HL, Hadem J, Leifeld L, Zachou K, Canbay A, 
Eisenbach C, Graziadei I, Encke J, Schmidt H, Vogel W, et al. Safety and efficacy of lamivudine in patients with severe acute or fulminant hepatitis $B$, a multicenter experience. J Viral Hepat. 2006;13:256-263.

13. Sylvia Brost, Paul Schnitzler, Wolfgang Stremmel, and Christoph Eisenbach, Entecavir as treatment for reactivation of hepatitis B in immunosuppressed patients. World J Gastroenterol. 2010 November 21; 16(43): 5447-5451.

14. Kondo M, Kitada N, Kobayashi M, Morita S, Yoshioka M, Tsuji T, Mori A, Okamoto T, Watari M. [A case of druginduced liver injury caused by entecavir for treatment of hepatitis $B$ virus reactivation during RCHOP in a patient with non-Hodgkin lymphoma] Gan To Kagaku Ryoho. 2009;36:1199-1201.
15. Lange CM, Bojunga J, Hofmann WP, Wunder K, Mihm $U$, Zeuzem S, Sarrazin C. Severe lactic acidosis during treatment of chronic hepatitis B with entecavir in patients with impaired liver function. Hepatology. 2009;50:2001-2006.

16. Girke J, Wedemeyer H, Wiegand J, Manns MP, Tillmann $\mathrm{HL}$ [Acute hepatitis B: is antiviral therapy indicated? Two case reports].[Article in German]. Source Zentrum Innere Medizin, Abteilung Gastroenterologie, Hepatologie und Endokrinologie, Med. Hochschule Hannover. Dtsch Med Wochenschr. 2008 May;133(22):1178-82.

17. Regev A. Preventing Hepatitis B Viral Reactivation in Patients Receiving Cancer Chemotherapy. Gastroenterol Hepatol (N Y). 2007 April; 3(4): 265-266. 